Mirai. Estudios Japoneses

ISSN-e: 1988-2378

http://dx.doi.org/10.5209/MIRA.57120

\title{
Reflexiones en torno a la imagen de Japón difundida por la prensa española en el tránsito hacia el Nuevo Régimen
}

\author{
Juan Ramón Ojeda García ${ }^{1}$
}

Resumen: En el presente artículo se pretende reflejar la imagen que había en España de Japón antes de su apertura en 1854. Para ello, se ha hecho un análisis de parte de la prensa española entre los años 1758 y 1800, con el objetivo de poseer una idea de la visión que se formarían todos aquellos lectores que acudieran a la misma; así como ver de qué modo se hablaba, cuáles eran las ideas más remarcadas, haciendo especial hincapié en apreciar si algunos de los tópicos aún presentes, lo estaban ya en aquellos momentos.

Palabras clave: Japón; España; medios de comunicación; Siglo XVIII.

[es]Reflections on the image of Japan disseminated by Spanish press during the transition towards the new regime

\begin{abstract}
The purpose of the present work is to present some findings about the image that Spain had of Japan before its opening in 1854. Findings, that are the result of a research that aimed to analyse the Spanish press from 1758 to 1800 in order to gain an idea of the vision that Spanish readers would have had of Japan at the time, as well as to see how the press spoke about Japan, which were the dominant ideas, trying to discover if some of the clichés about Japan which are still present today, were existent at that time.
\end{abstract}

Keywords: Japan; Spain; mass media; $18^{\text {th }}$ century.

Sumario. 1. Hacia un estado de la cuestión. 2. La imagen de Japón difundida en la prensa española entre 1758 y 1800 .

Cómo citar: Ojeda García, J. R. (2017). Reflexiones en torno a la imagen de Japón difundida por la prensa española en el tránsito hacia el Nuevo Régimen (2017), en Mirai. Estudios Japoneses 1, 2017, 307-316.

\section{Hacia un estado de la cuestión}

A día de hoy, Japón sigue siendo un país poco estudiado y comprendido en Occidente, no siendo España una excepción en ello. Sobre el mismo, se suele poseer una imagen repleta de tópicos, que comúnmente se asocia a la visión aportada por los viajeros que allí acudieron, una vez que el país salió de su aislamiento internacional en 1853. De hecho, suele decirse que es a partir de entonces cuando el país del Sol Naciente comenzó a ser descubierto en Occidente en mayor medida, aun siendo

\footnotetext{
1 Universidad de Sevilla. Acción financiada por el V Plan Propio.

juan-ramon--@hotmail.com
} 
conscientes de que ya a finales del XVI y comienzos del XVII se habían producido los primeros contactos entre japoneses y europeos. Se han hecho algunos estudios, tanto en España como en otros países occidentales, sobre la imagen que se tuvo de Japón a partir de su apertura e incluso sobre la que actualmente se posee. Sin embargo, aún no ha sido estudiada la idea que había de dicho país durante su aislamiento. Un escaso conocimiento sobre dicho país que no se da solamente a nivel general, sino incluso en el mundo académico; ya que, son pocos los centros universitarios, que ofrecen en sus programas asignaturas relacionadas con la historia y la cultura niponas. Sin embargo, este panorama parece estar cambiando en los últimos años gracias al esfuerzo diverso y múltiple, llevado a cabo por diversas universidades y asociaciones $^{2}$, pero común en cuanto al fin u objetivo principal a conseguir: el de contribuir al conocimiento de Japón entre la población española. Un objetivo principal que comparte el presente artículo.

Concretamente, pretendemos contribuir al campo de estudios sobre la imagen de Japón difundida en España. Sobre tal asunto, cabe decir que es un terreno prácticamente virgen, donde debemos destacar la excelente labor llevada a cabo por V. David Almazán Tomás, con su tesis de licenciatura ${ }^{3}$, donde realiza una revisión de la imagen dada de dicho país y del japonismo (influencia de las artes niponas en las occidentales) en la revista cultural española La Ilustración Artística publicada entre 1882 y 1916 , o su tesis doctoral ${ }^{4}$, en la que amplía el análisis en un mayor número de publicaciones. De igual modo, ha publicado diversos artículos que analizan la imagen de Japón, o ciertos aspectos de la misma, en España ${ }^{5}$. Una labor en la que, aunque Almazán sea quizás uno de los máximos exponentes, destacan también otros especialistas centrados no tanto en la imagen difundida en la prensa sino en otras fuentes, como puede ser el caso de Elena Barlés Báguena con artículos dedicados a estudiar el arte Namban o los libros de

2 Cabe destacar la labor emprendida por algunas universidades, como la Universidad de Sevilla (con la creación reciente del Grado en Estudios de Asia Oriental en colaboración con la Universidad de Málaga), la Universidad Autónoma de Madrid, la Universidad Complutense de Madrid o la Universitat Oberta de Catalunya entre otras. Además, cada vez son más las asociaciones o fundaciones que ayudan a difundir conocimientos sobre Japón entre la población española, tales como: Japan Foundation o Fundación Japón de Madrid, AEJE (Asociación de Estudios Japoneses en España), Fundación Instituto de Japonología, etc. Labor a nivel nacional, que viene acompañada por el esfuerzo realizado por otras organizaciones a nivel autonómico, tales como ADEC JAP-AN (Asociación para la Difusión y el Estudio de la Cultura Japonesa en Andalucía) o Nihon Yūkōkai de Asturias (Asociación de Amigos de Japón). Y no menos reconocimiento merecen las editoriales que contribuyen con la publicación de obras que ayudan en dicha labor, siendo un buen ejemplo a destacar Satori Ediciones, que como ella misma se define es una "editorial especializada en cultura y literatura japonesa".

3 Véase un resumen de la misma en AlmazÁn Tomás, V. David (1997): "Japón y el japonismo en La Ilustración Artística”, Artigrama: Revista del Departamento de Historia del Arte de la Universidad de Zaragoza, $\mathrm{n}^{\circ} 12$ (1996-1997), Zaragoza, Universidad de Zaragoza, pp.706-709.

4 Almazán Tomás, David V. (2001): Japón y el japonismo en las revistas ilustradas españolas (1870-1935): introducción a las revistas ilustradas como fuente de documentación de Japón y el "Japonismo”. Zaragoza: Prensas Universitarias de Zaragoza.

5 Pueden citarse como ejemplo: Almazán Tomás, David V. (2004): “Geisha, esposa y feminista: imágenes de la mujer japonesa en la prensa española (1900-1936)", Studium: Revista de humanidades, $\mathrm{n}^{\circ} 10$, Teruel, Colegio de Teruel, pp.253-268; Barlés BÁguena, Elena / Almazán Tomás, V. David: "El mundo actual y Japón desde España”. En: Barlés Báguena, E. y Almazán Tomás, D. V. (coords.) (2011): Japón y el mundo actual, Zaragoza, Prensas Universitarias de Zaragoza, pp.11-21. 
viajeros ${ }^{6}$, o de Uno Kazumi ${ }^{7}$ y Nagase Yumi $^{8}$, que se han encargado igualmente de analizar la imagen de Japón en España difundida en otros soportes. Esfuerzos a la inversa, dedicados a estudiar la imagen de España en Japón, han sido llevados a cabo de igual manera por autores como Anjhara Gómez Aragón?

Una labor que, gracias a todos estos especialistas, va ampliando nuestros conocimientos sobre Japón y nos permite ir más allá de la imagen que se tiene por regla general sobre dicho país, en la que están constantemente presentes los clichés y tópicos. Un esfuerzo por pasar de considerar a Japón simplemente como un país de geishas y samuráis; o, como actualmente se suele considerar, del sushi, manga y anime. Por ello, todas estas publicaciones nos hacen ver cómo esa imagen se ha ido construyendo. Sin embargo, como hemos podido observar, todas ellas se centran en el momento en el que tuvieron lugar los primeros contactos antes del aislamiento (entre finales del XVI y comienzos del XVII), o a partir de su apertura en 1854 y la Restauración Meiji en 1868, en la que Japón comenzó a ser cada vez más visitado, despertando un enorme interés y curiosidad en Occidente.

Por ello, vemos cómo hay un claro vacío en el estudio de la imagen existente sobre Japón en España en ese período intermedio de aislamiento. No se ha investigado qué es lo que se sabía de dicho país, qué tópicos estaban ya presentes, qué aspectos llamaban la atención, etc.

Así, como su propio título indica, nuestra investigación, pretendía con toda la humildad posible (como objetivo específico) apreciar cuál era la visión que se difundía de dicho país oriental en la prensa española de esos años; analizando, para ello, qué es lo que sabía por aquel entonces de Japón e intentando indagar si muchos de los tópicos actualmente ligados al imaginario de lo japonés, estaban ya presentes en aquella época. Con ello, procuramos simplemente comenzar un sendero, que lógicamente puede ser mejorado y ampliado por futuras investigaciones. Un esfuerzo, que como ya antes hemos dicho, pretendemos abarcar con humildad, para así poner nuestro grano de arena en esta enorme e interesante labor de hacer a Japón cada vez más entendido y comprendido en nuestro país.

El hecho de que tomáramos como inicio la fecha de 1758, se debe a que es precisamente en ese año cuando surgió el considerado primer diario español: el Diario

6 Barlés Báguena, Elena (2013): “Testimonios de un viaje y un encuentro durante el siglo ibérico en Japón (1543-1643). La imagen del 'otro' en las representaciones pictóricas del arte Namban”. En: GarcÉs GarCíA, Pilar y Terrón Barbosa, Lourdes (coords.). Itinerarios, viajes y contactos Japón- Europa. Berne: Peter Lang, pp.119-150. Destaca igualmente: BARLÉs BÁGuena, Elena (2008): "La mujer japonesa en los libros de viajeros publicados en castellano a finales del siglo XIX y primeras décadas del siglo XX”. En: BARLÉs BÁGUENA, Elena y AlmazÁn Tomás, David V. (coords.). La mujer japonesa: realidad y mito, Zaragoza: Prensas Universitarias de Zaragoza, pp.773-848.

7 Uno, Kazumi (2004): "La imagen de Japón en los libros para niños publicados en España", Anuario de investigación en literatura infantil y juvenil, $\mathrm{n}^{\circ}$ 2, Vigo, ANILIJ, pp. 231-250.

$8 \quad$ Nagase, Yumi (2004): “La imagen de Japón a través de la fuente misional (1914-1923): la figura del emperador”, en AlmazÁn Tomás David V. (coord.), Japón: arte, cultura y agua, Zaragoza, Prensas Universitarias de Zaragoza, pp.331-340.

9 Véase Gómez Aragón, Anjhara (2010): “La imagen de Andalucía en el turismo cultural. El caso de Japón”. En: Jiménez Caballero José Luis y De Fuentes Ruiz, Pilar (coords.), Nuevas perspectivas del turismo para la próxima década: III Jornadas de Investigación en Turismo, Sevilla, Edición Digital@tres, 2010, pp.643-663.; GóMEZ ArAGón, Anjhara (2013): "Imaginarios sobre España en el turismo japonés. Confusiones históricas, patrimonio y simbolismo recreado". En: Garcés García, Pilar y Terrón Barbosa, Lourdes (coords.). Itinerarios, viajes... op. Cit., pp.447-460.; Gómez Aragón, Anjhara (2011): "Interpretaciones mutuas entre España y Japón: imágenes construidas". En: Cid LuCAs, Fernando (coord.), Japón y la Península Ibérica: Cinco siglos de encuentros, Gijón, Satori Ediciones, pp. 55-72. 
noticioso. Antes ya existía prensa en nuestro país, pero no de frecuencia diaria. Por ello, hemos comenzado en dicho año y con dicho periódico, al ser una publicación que, como ella misma afirmaba, pretendía dirigirse al gran público en general y no a un sector en concreto.

Así, a partir de 1758 fuimos rastreando la prensa española publicada desde entonces hasta 1800, en busca de noticias, artículos o referencias relacionadas con Japón. La fecha de 1800, la tomamos como cierre debido a los límites de extensión a los que obliga a atenerse una investigación, aunque el hecho de que sea concretamente ese el año elegido, se debe a que es el que marca el comienzo de un nuevo siglo, en el que se producirán muchos cambios respecto al anterior en todo el mundo y, por ende, en España con la invasión napoleónica en 1808 y la llegada de los ideales revolucionarios. Con estas fechas así establecidas, pretendemos analizar la imagen difundida de Japón en España en la segunda mitad del siglo XVIII.

El motivo por el que elegimos la prensa como fuente principal se debe a que es un medio de difusión de conocimientos y de ideas por aquel entonces tal vez de mayor calado que un libro, al llegar a más personas y al ser más asequible. Así, muchas personas leerían cosas sobre Japón sin buscarlas. No tendrían que acudir a libros sobre el mismo, sino que gracias a la prensa poseerían la misma información sin pretenderlo.

En cuanto a la metodología se refiere, comenzamos con la localización de toda referencia ligada al país nipón en la prensa española de ese período. Así, ante la prácticamente imposibilidad de abarcar toda la prensa española de esos momentos, analizamos la presente en formato digital en la hemeroteca digital de la Biblioteca Nacional de España $(\mathrm{BNE})^{10}$. Una selección de periódicos bastante completa, que nos permitió realizar un sondeo considerable sobre el tema pretendido ${ }^{11}$.

10 Biblioteca Nacional de España, Hemeroteca Digital. Biblioteca Nacional de España [página WEB], Ministerio de Educación, Cultura y Deporte. Disponible en: http://www.bne.es/es/Catalogos/HemerotecaDigital/ [Consulta: 1-1-2014].

11 Dentro de los diecisiete periódicos analizados, sólo en diez de ellos encontramos al menos una referencia en torno al país del Sol Naciente:

1. Diario noticioso (también conocido a lo largo de su historia como Diario noticioso universal; o, como Diario noticioso, curioso, erudito y comercial público y económico).

2. Diario de Madrid.

3. Diario curioso, histórico, erudito, comercial, civil y económico.

4. Correo de Madrid (también conocido como Correo de los ciegos de Madrid).

5. Mercurio de España.

6. Correo mercantil de España y sus Indias.

7. Semanario Económico.

8. Espíritu de los mejores diarios literarios que se publican en Europa.

9. Semanario de agricultura y artes dirigido a los párrocos.

10. Semanario de Zaragoza.

Los otros siete periódicos analizados y en los que no hemos localizado ninguna referencia son los siguientes:

1. Kalendario manual y guía de forasteros en Madrid. (1744-1837). Frecuencia: Anual.

2. Diario de Valencia. (1 de enero de 1790-1835/6), aunque solamente se ha podido consultar los digitalizados en la BNE, que se sitúan entre el 20 de enero de 1795 y el 29 de enero de 1833.

3. Semanario de Salamanca. (15 de marzo de 1794-30 de octubre de 1798), en el que al igual que sucedía en el caso anterior hemos podido analizar solamente los disponibles en formato digital: (15 de marzo de 1794-27 de septiembre de 1796). Frecuencia: Bisemanal (martes y sábados).

4. Mercurio histórico y político. (1738-1783). Frecuencia: Mensual. Este podría ser considerado la excepción del grupo, ya que Japón aparece nombrado en cuatro ocasiones ("Noticias de Francia", Mercurio histórico y político, junio 1772, p. 52.; "Obras de Lope de Vega", Mercurio histórico y político, diciembre 1775, p. 106.; "Discurso histórico y político sobre los principales sucesos del año 1775", Mercurio histórico y po- 
Tras la recopilación de toda esa información, pasamos a analizarla detenidamente para apreciar cuáles eran las ideas básicas difundidas en torno a Japón. Así, ante la diversidad de temas surgidos, decidimos clasificarlos en grandes grupos temáticos, con diversos subapartados, que engloban diversas ideas ${ }^{12}$.

Por citar un ejemplo, podemos destacar cómo en el primer grupo denominado "EL TERRITORIO", insertamos en subapartados diferenciados las ideas constantes que se difunden en torno al mismo, como la de multitud de islas, la enorme extensión del mismo o su montuosidad.

Cada apartado (o subapartado), comienza con una breve explicación sobre el fenómeno, elemento o asunto sobre el que se esté hablando, en el que se intenta hacer constar unas ideas básicas sobre los mismos; para continuar, posteriormente, con el análisis de la imagen que se da de ellos en la prensa analizada. Con ello, pretendemos introducir al lector sobre el asunto a tratar, para que sepa qué era realmente el elemento estudiado y pueda así apreciar la diferencia existente (o no) respecto a la imagen que se da del mismo. Así, por mencionar un ejemplo, antes de explicar qué imagen se difundía de los samuráis y qué es lo que se hablaba en la prensa analizada sobre ellos, se dan unos breves apuntes sobre el mismo. Por ello, como es lógico, tuvimos que recurrir a una bibliografía muy diversa sobre Japón, en la que se abordan cada uno de los elementos seleccionados.

Con ello, como antes dijimos, pretendimos apreciar cuál era la imagen que se difundía de Japón después del cierre (y aislamiento del contacto internacional) a partir de las medidas adoptadas desde 1633 y antes de la salida del mismo en 1853-4. Así, nuestra intención era la de conocer si ya en esos momentos se encontraban algunos de los tópicos aún existentes, qué nivel de conocimiento existía y se difundía entre la

lítico, enero 1776, p. 13.; "Noticias de Francia”, Mercurio histórico y político, enero 1779, p. 45.), aunque en tres de ellas como mera referencia geográfica y en una como mención al título de una obra denominada "Mártires del Japón"; es decir, sólo aparece el nombre "Japón" sin ninguna información complementaria.

5. Diario evangélico, histórico-político. (1 de junio de 1772-6 de junio de 1772).

6. Diario pinciano. (febrero de 1787-abril de 1788). Frecuencia: Semanal.

7. Semanario erudito y curioso de Salamanca. (1 de octubre de 1793-11 de marzo de 1794). Frecuencia: Bisemanal (martes y sábados).

12 Sobre el territorio, primer apartado, las principales ideas difundidas hablan de la multitud de islas que conforman el país, así como de lo vasto y montañoso que es el mismo. Respecto a la población y poblamiento, segundo apartado, se dice que el país estaba muy poblado, se da una imagen bastante fiel de la ciudad y los castillos japoneses ideales, y se llega a hablar de los ainus. Desgraciadamente, hemos tenido que dedicar un apartado a las catástrofes naturales, debido a la constante presencia de los mismos en la imagen difundida, siendo los incendios y tifones los principales protagonistas. La economía posee la identidad suficiente como para poseer un apartado propio, en el que se destaca la riqueza del país, así como el sake y el té como productos a resaltar dentro de la misma. No menos importante son los contactos exteriores, o mejor dicho la ausencia de los mismos, así dedicamos diversos subapartados destinados a comentar la inaccesibilidad o reclusión del país, la lucha contra el Cristianismo y la idea de curiosidad despertada entre los japoneses durante los primeros contactos. Son muchas las referencias a determinadas costumbres niponas, por lo que como es lógico otro de los apartados se dedica a las mismas; concretamente, se menciona la forma de sentarse, la de saludar, los cantos y gesticulaciones, el ohaguro (costumbre que consistía en pintarse los dientes de negro), la presencia omnipresente del arroz en lugar del pan en las comidas, la escritura y la vestimenta. Como no puede ser de otro modo, la figura del samurái posee un apartado propio, en el que se abordan como subapartados la figura en sí, la katana y el seppuku en relación al código de honor. Otras figuras no menos importante también abordadas en la prensa española, como son la del emperador, shogun, daimio y las cortesanas son abordadas en otro apartado independiente. En el apartado de la religión, se trata la misma, la figura de los bonzos y las creencias de la población en uno de los subapartados, mientras que en otro debido a su importancia se aborda la danza y el teatro (no debe olvidarse el carácter sacro de los mismos). El último apartado está destinado a comentar la imagen difundida sobre la justicia, en la que predomina la idea de severidad y excesivos castigos penales. 
población, si ya se hablaba de algunos elementos característicos (como el samurái, el shōgun, el sake, etc.) y si estos se conocían por su nombre japonés.

\section{La imagen de Japón difundida en la prensa española entre 1758 y 1800}

Por todo ello, como pudimos observar a lo largo de todo el estudio realizado, son muchos los temas y asuntos abordados sobre Japón en la prensa analizada, por lo que dicho país no sería tan desconocido para todo aquel que se acercara a la misma. De hecho, a pesar de lo que se podría pensar en un primer momento, no existía un desconocimiento tal como para que haya que esperar a la apertura del país en 1854 para poseer una imagen bastante exacta sobre el mismo.

Lógicamente, con dicha apertura y la llegada de los nuevos viajeros y el surgimiento de los primeros japonólogos, se conseguirá un conocimiento más profundo; pero, lo que a nosotros nos interesa, es señalar la existencia de un conocimiento sobre Japón bastante completo en esos años analizados entre 1758 y 1800 . Un conocimiento que, si bien es cierto que resulta superficial en muchos aspectos y no entra en buscar explicaciones detalladas como luego se hará, permitió imaginar un Japón muy cercano al real.

Como hemos podido apreciar, se conocían muchos rasgos sobre su territorio (como la multitud de islas que lo componen, la montuosidad del terreno, la extensión aproximada del mismo, etc.), sobre la población y sus costumbres; de igual modo, se sabía que era un país azotado por las catástrofes naturales y se conocerían algunos aspectos acerca de su religión, teatro, etc. Muestra de ello, son algunos de los siguientes fragmentos:

Estas Islas están situadas en el Mar de la China, entre los treinta y uno, y cuarenta grados de latitud; y distan del continente, por algunas partes, doscientas y ochenta leguas, y por otras solo sesenta. Las tres principales son, Niphon, donde se halla Meaco, la Ciudad más interesante de todas las Islas para el Comercio; Ximay, y Xicocun, un gran número de otras pequeñas Islas las cercan; pero son poco conocidas de los Europeos $[\ldots]^{13}$

[...] el País es montuoso, muy fértil y abundante en metales...En su País se observan dos montes grandes: el uno llega hasta las nubes, y el otro es un volcán que siempre despide llamas ${ }^{14}$.

Pasaron por entre muchas Islas, que las más le parecieron muy pobladas, y llenas de hermosas Ciudades $[\ldots]^{15}$.

Pero prescindiendo de estos argumentos de que están llenos los libros, consideremos la belleza como un producto de la imaginación, y hallaremos que ninguna otra idea hay más dependiente del capricho [...] En Siam, en el Japón y en las Islas Marianas es gran deformidad tener los dientes blancos, porque dicen que parecen perros, y así es costumbre general en aquellos países teñirlos de rojo, o de negro ${ }^{16}$.

\footnotetext{
"Islas del Japón”, Diario noticioso universal, No 72, 29/03/1760, p. 2.

"Literatura y comercio. Lausana", Espíritu de los mejores diarios literarios que se publican en Europa, № 235, 31/05/1790, p. 14.

15 "Historia general de los viajes", Diario noticioso universal, No 552, 8/07/1762, p. 1.

16 "Sobre la belleza", Diario de Madrid, No 290, 17/101794, p. 1.
} 
Los vientos impetuosos, que nombran huracanes los marineros europeos, y que tienen aquí el nombre de Tiphons, se experimentan en esta costa y en los mares vecinos con terribles estragos $[\ldots]^{17}$.

Por todo ello, una imagen bastante completa que permitiría conocer los rasgos principales de aquel país tan lejano, que como ya comentamos se encontraba aislado del mundo desde comienzos del siglo XVII.

Precisamente de aquellos momentos, finales del siglo XVI y comienzos del siglo XVII, proceden la mayoría de las fuentes principales para los conocimientos difundidos sobre Japón en la prensa analizada. Es, por ello, por lo que algunos aspectos integrantes en la imagen dada sobre Japón son anacrónicos. Muestra de ello, puede ser el contexto de guerra y conspiraciones que aparecía asociado a los castillos japoneses ${ }^{18}$; cosa, que era inexacta, ya que si bien es cierto que en los momentos en los que se produjeron esos primeros contactos entre Japón y Occidente se vivía aquella realidad, en los años de nuestro análisis, no era tal, dándose más bien un período de paz y estabilidad. Otro ejemplo puede ser la ausencia prácticamente de referencias a la floreciente vida urbana (conocida como "mundo flotante") que comenzó a aparecer tras el aislamiento, en la que se desarrollaron muchos elementos (como las geishas o los grabados $u$ kiyo- $e^{19}$ ) que posteriormente con la apertura del país, al ser conocidos por los occidentales, fueron ligados indisociablemente al imaginario de lo japonés. Un anacronismo, por tanto, ligado al hecho de que las fuentes principales existentes sobre el país nipón y de las cuales bebía dicha prensa pertenecían a un momento anterior. Sin embargo, exceptuando algunos elementos como los anteriormente mencionados, ese anacronismo pasa prácticamente desapercibido, al no ser muy distinta (generalmente hablando) la imagen de Japón en esos momentos de finales del siglo XVI y comienzos del XVII, a la de 1758-1800. El país no había cambiado tanto debido al aislamiento, o al menos no tanto como sucedería a partir de 1853 cuando entre en contacto con Occidente y lleve a cabo su modernización; es decir, más que no cambiar, lo que consiguió el aislamiento fue retrasar la occidentalización y sus consiguientes efectos.

Así, en contra de lo que se pudiera pensar, a pesar del aislamiento en el que se encontraba sumido el país nipón hasta mediados del siglo XIX, no era para nada desconocido para los lectores de la prensa española de la segunda mitad del siglo XVIII.

Otro de los aspectos que debemos destacar, es el hecho de que se encuentre una profundización cada vez mayor a medida que vamos avanzando en el tiempo. Ejemplo de ello, puede ser la evolución que destacamos en la percepción de la

17 "Historia general de los viajes", Diario noticioso universal, No 7464, 1 de octubre de 1773, pp. 1-2.

18 Esto puede apreciarse en algunos de los siguientes artículos, donde entre otros acontecimientos se nos habla del castillo de Osaka y de su papel en el transcurso de la toma del poder de parte de Tokugawa Ieyasu (enfrentamiento con Toyotomi Hideyori, "el sitio de Osaka"): "Historia general de los viajes", Diario noticioso universal, $\mathrm{N}^{\mathrm{o}}$ 553, 9 de julio de 1762, p. 1; "Historia general de los viajes", Diario noticioso universal, № 583, 13 de agosto de 1762, p. 2.; "Historia general de los viajes", Diario noticioso universal, № 588, 19 de agosto de 1762 , p. 2; "Historia general de los viajes", Diario noticioso universal, No 589, 20 de agosto de 1762, p. 1., "Historia general de los viajes", Diario noticioso universal, $N^{\circ} 4469,1$ de octubre de 1772, pp. 1-2.; etc.

19 Con dicho nombre, o con el de "pinturas del mundo flotante", se conoce a un género de grabado con planchas de madera desarrollado en Japón entre los siglos XVII-XX. Género, que con la apertura del país en 1854, será uno de los más admirados en Occidente, dejando una honda impresión en artistas tales como Vincent van Gogh. 
figura del daimyō, que de ser nombrado "rey" en las primeras noticias localizadas, pasará a ser denominado "gobernador" posteriormente, antes de ser llamado por su nombre, daimyō, por primera vez en 1791:

Manteniéndose el Rey más de una hora en el Navío, entró en su Galera, y se volvió a la Ribera; pero toda la Nobleza que lo había acompañado, quiso visitar también a los Ingleses $[\ldots]^{20}$.

El 7, el Rey de la Isla de Goto, que no está muy distante de la de Firando, llegó a hacer una visita al Rey de Toyna, su pariente, y aliado ${ }^{21}$.

Fueron llevados después al Palacio del Gobernador, al cual se presentaron al mediodía. Satisfecha su curiosidad por la relación de sus aventuras $[\ldots]^{22}$.

En la octava escena se figuraba el tren pomposo de un Daimio, que iba de viaje, y era cosa de ver ${ }^{23}$.

También a la hora de abordar la religiosidad nipona vimos cómo se pasaba de una crítica negativa en los primeros momentos, a un intento de acercamiento más comprensivo y objetivo en $1788^{24}$. Y lo mismo en el caso del teatro ya en pleno $1800^{25}$. Así, aunque solamente sea apreciable en algunos temas como los anteriormente citados, hemos considerado oportuno señalar el mayor esfuerzo de comprensión que se lleva a cabo en esos últimos doce años analizados, contribuyendo gratamente en dicha labor el Diario de Madrid, con artículos verdaderamente admirables para la época ${ }^{26}$. Sin embargo, dicho avance en el conocimiento no viene de la nada, sino que como cabría esperar estaba apoyado en obras extranjeras (principalmente holandesas), fruto de viajes más recientes ${ }^{27}$.

De igual modo, vemos cómo se conocen algunos elementos (como la figura del samurái, el sake o el seppuku entre otros), aunque no por su nombre. Se prefiere emplear términos occidentales que ayuden a entender la cultura nipona, tan compleja y en muchos casos incomprendida aún en la actualidad. Así, en lugar de "samurái" se habla de "soldado", en lugar de "sake" se habla de "vino de arroz", etc., sin que ello signifique que eran elementos desconocidos:

20 "Historia general de los viajes", Diario noticioso universal, № 548, 03/07/1762, p. 1.

21 "Historia general de los viajes", Diario noticioso universal, No 550, 06/07/1762, p. 2.

22 "Historia general de los viajes", Diario noticioso universal, No 3568, 07/09/1769, p. 2.

23 "Fin de la noticia curiosa y entretenida de la fiesta del Matsuri", Diario de Madrid, No 265, 22/09/1791, p. 2.

24 "Moral. Extrañas ceremonias legales de la Religión llamada Sintos en el Japón”, Diario de Madrid, № 230, 17/08/1788, pp. 2-3; "Fin de la noticia sobre las ceremonias de la Religión llamada Sintos en el Japón”, Diario de Madrid, $\mathrm{N}^{\mathrm{o}} 231,18 / 08 / 1788$, pp. 1-2.

25 "Discurso sobre el amor que tienen casi todos los pueblos a la poesía dramática", Diario de Madrid, No 279 , 06/10/1800, pp. 1-2.

26 Consúltese: "Amor filial. Extraña y laudable acción de tres hijos para socorrer a su pobre madre, en el Imperio del Japón”, Diario de Madrid, No 339, 05/12/1791, pp. 1-2; "Descripción puntual y curiosa del famoso Palacio del Dayro, Príncipe eclesiástico del Japón, en la Ciudad de Meaco, Capital de aquel Imperio”, Diario de Madrid, $\mathrm{N}^{\mathrm{o}} 364,30 / 12 / 1791$, pp. 1-3; "Extraños usos y costumbres de sociedad entre diferentes Pueblos y Naciones. Espíritu de los usos y costumbres de diferentes Pueblos", Diario de Madrid, No 150, 29/05/1792, pp. 1-3; "Fin de la Historia geográfica de ayer", Diario de Madrid, No 346, 12/12/1791, pp. 1-3; "Literatura", Diario de Madrid, $\mathrm{N}^{\mathrm{o}} 62,03 / 03 / 1800$, p. 2; "Noticia entretenida y curiosa de la fiesta del Matsuri, o función Teatral que usan los Japoneses en obsequio de sus Héroes pasados", Diario de Madrid, No 264, 21/09/1791, pp. 1-3; "Pintura y descripción de la magnífica pompa, y suntuoso aparato con que el Cubo, Emperador secular del Japón, va a visitar al Dayro, Príncipe Eclesiástico, desde Yedo, a Meaco", Diario de Madrid, No 345, 11/12/1791, pp. 1-4.

27 Un ejemplo de ello es la utilización de parte de la producción de Engelbert Kaempfer (1651-1716). 
Los japoneses dijeron a Saris, que estaba destinado para llevar Soldados a las Islas, luego que había Guerra, o alguna sublevación ${ }^{28}$.

Cada uno tenía al lado dos Katans, que son las espadas del País; una de media vara de largo, y otra de un palmo. Llevaban desnudo el cuello, y la mitad de la cabeza raída por delante, y los demás cabellos, que eran muy largos, formaban un nudo por detrás, descubiertos, sin gorro, ni turbante [...] Por única Escolta, al subir al Navío, acompañaba a cada uno un Oficial, que tenía el mando de sus Esclavos ${ }^{29}$.

La bebida común del Pueblo es agua pura, que calentándola un poco, la miran como un preservativo soberano contra las lombrices. Su único licor es una destilación de arroz, casi tan fuerte como el aguardiente de Francia, y parecido en el color al vino de Canarias $[\ldots]^{30}$.

Como pudimos apreciar, se hablaba de sus características y se daba sobre los mismos una imagen bastante cercana a la real. Se buscaba explicar aquella cultura tan "exótica" bajo patrones mentales occidentales; aunque a veces, con ello, se produjeran ciertas inexactitudes que podían distorsionar la imagen dada, como puede ejemplificarse en el hecho de denominar "emperador" al "shogun" o "sumo pontífice" al "emperador":

La Religión, pues, de Sintos tiene por Jefe, y Soberano Pontífice de su observancia al Mikiddo, que comúnmente se llama el Dayro, o Emperador Eclesiástico (distinto del Cubbo, o monarca secular) $[\ldots]^{31}$.

El Emperador Cubo, usurpó la Japonia el año 1559 y Gobierna despóticamente sus vasallos, que siempre fueron Idólatras, por lo cual San Francisco Xavier, fue allá el año 1549 a Predicarles el Evangelio $[\ldots]^{32}$.

Por ello, habrá que esperar a mediados del siglo XIX con la apertura del país nipón para que se empiece a nombrar a las cosas por el término japonés propio y aparezcan por primera vez ciertos nombres como samurái, sogún, sake, seppuku o harakiri, etc. Sin embargo, aunque se utilizaran por primera vez, no es entonces cuando se hacían visibles para los occidentales, sino que como hemos podido apreciar muchos de esos elementos ya eran conocidos y difundidos por la prensa española.

Ligado a ello, podríamos decir que ya en estos años se iría formando, debido a la información difundida en la prensa, una imagen sobre Japón en la que ya estarían presentes muchos de los actuales tópicos sobre el país. Fue con su difusión en esa prensa, cuando estuvo al alcance de un mayor número de personas. No había que acudir a libros específicos sobre el país para saber del mismo, sino que dicha información les llegaba sin ellos quererlo ni pretenderlo. Que luego leyeran dichos artículos o entendieran lo que en ellos se comentaba es distinto, pero lo que no se

\footnotetext{
"Historia general de los viajes", Diario noticioso universal, No 552, 08/07/1762, p. 2.

"Historia general de los viajes", Diario noticioso universal, No 547, 02/07/1762, p. 2.

"Historia general de los viajes", Diario noticioso universal, No 554, 10/07/1762, p. 1.

“Moral. Extrañas ceremonias legales de la Religión llamada Sintos en el Japón”, Diario de Madrid, No 230, 17/08/1788, pp. 2-3.

32 "Geografia. Las islas de la Asia", Diario curioso, Histórico, Erudito, Comercial, Civil, y Económico, № 203, 26/12/1772, p. 3 .
} 
puede negar es que gracias a la prensa la información sobre Japón era más accesible y de un mayor dominio público.

Así, aunque siempre se suele suponer y comentar que es a partir de la apertura del país nipón en 1854, con la salida del aislamiento en el que se encontraba y con la llegada de nuevos extranjeros, cuando se comienza a hablar de nuevo de Japón; nosotros, hemos podido comprobar cómo no fue así. No hubo que esperar a mediados del siglo XIX, aunque lógicamente gracias a los nuevos contactos e información recaudada se profundizará a partir de entonces en lo ya conocido, se conocerán nuevos aspectos y se comenzará a llamar a las cosas por su nombre.

Por ello, como conclusión, entre 1758 y 1800, la prensa se encargó de difundir entre sus lectores una imagen sobre Japón bastante fiel a la realidad en muchos aspectos, en la que ya aparecen presentes muchos de los tópicos sobre el país nipón. Imagen, que lógicamente a partir de mediados del XIX, se verá enriquecida gracias a la profundización llevada a cabo y al conocimiento de nuevas ideas y elementos antes desconocidos. Sin embargo, no se partía de cero como se podría haber pensado. 